Arq. Bras. Med. Vet. Zootec., v.68, n.1, p.201-207, 2016

\title{
Digestibilidade de nutrientes em rações de frangos de corte suplementadas com promotores de crescimento
}

[Nutrient digestibility in diets for broilers supplemented with growth promoters]

\author{
L. Borsatti ${ }^{1}$, R.V. Nunes ${ }^{2}$, R.A. Schone ${ }^{2}$, R. Frank ${ }^{2}$, J.L. Schneiders ${ }^{2}$, T.L. Savoldi ${ }^{2}$ \\ ${ }^{1}$ Universidade Federal do Rio Grande do Sul -Porto Alegre, RS \\ ${ }^{2}$ Universidade Estadual do Oeste do Paraná - Marechal Cândido Rondon, PR
}

\begin{abstract}
RESUMO
Um experimento foi realizado para avaliar o efeito da utilização de diferentes promotores de crescimento sobre o metabolismo de frangos de corte em crescimento. Foram avaliadas duas dietas, uma atendendo às exigências nutricionais de frangos de corte (normal) e uma dieta reduzida, com 5\% a menos da exigência nutricional (reduzida), suplementadas ou não com antibióticos e prebióticos. Foram utilizados 180 pintos de corte criados em galpão convencional, com cama de maravalha, até os 21 dias de idade. Em seguida, foram divididos em 36 gaiolas, distribuídos em delineamento experimental inteiramente ao acaso, utilizando método tradicional de coleta de excretas. Houve interação $(\mathrm{P}<0,05)$ entre dieta e promotores de crescimento para os coeficientes de digestibilidade ileal da matéria seca (CDIMS), da proteína bruta (CDIPB) e do extrato etéreo (CDIEE). A dieta reduzida contendo antibiótico apresentou menor CDIMS. A dieta normal contendo antibiótico apresentou maior CDIPB $(\mathrm{P}<0,05)$, enquanto a dieta reduzida contendo prebiótico apresentou melhor CDIPB e CDIEE $(\mathrm{P}<0,05)$. Os valores dos coeficientes de digestibilidade total da matéria seca (CDTMS), da proteína bruta (CDTPB) e do extrato etéreo (CDTEE) apresentaram interação $(\mathrm{P}<0,05)$ entre dietas e promotores de crescimento, em que a dieta reduzida contendo antibiótico apresentou menor CDTMS e CDTEE. A dieta normal apresentou maiores valores de energia metabolizável aparente (EMA) e EMA corrigida para balanço de nitrogênio (EMAn) $(\mathrm{P}<0,05)$. Concluiu-se que, ao se reduzir a exigência nutricional da ração, a digestibilidade dos nutrientes foi reduzida, no entanto os óleos essenciais promoveram aumento nos coeficientes de digestibilidade ileal da matéria seca, da proteína bruta e do extrato etéreo.
\end{abstract}

Palavras-chave: óleos essenciais, aditivos, frutoligossacarídeos

\begin{abstract}
An experiment was conducted to evaluate the effect of using different growth promoters on the metabolism of growing broilers. We evaluated two diets, one meeting the nutritional requirements of broilers (normal) and another reduced diet with 5\% less than the nutritional requirement (reduced), supplemented or not with antibiotics and prebiotics. A total of 180 broiler chicks reared in shed masonry and wood shaving bedding until 21 days of age. The animals were divided into 36 cages and distributed in a completely randomized design, using a traditional method of excreta collection. There was an interaction $(P<0.05)$ between diet and growth promoters for ileal digestibility coefficient of dry matter (IDCDM), crude protein (IDCCP) and ether extract (IDCEE). The reduced diet containing antibiotics had lower IDCDM. The normal diet containing antibiotic had higher IDCCP $(P<0.05)$, whereas the reduced diet containing prebiotic showed better IDCCP and IDCEE $(P<0.05)$. The values of total digestibility coefficient of dry matter (TDCDM), crude protein (TDCCP) and ether extract $(T D C E E)$ showed interaction $(P<0.05)$ between diets and growth promoters, where the reduced diet containing antibiotics had lower TDCDM and TDCEE. A normal diet had higher apparent metabolizable energy (AME) and AME corrected for nitrogen balance (AMEn) $(P<0.05)$. It was concluded that when the nutritional requirement of diet was reduced, the nutrients digestibility was also reduced, however essential oils caused an increase in ileal digestibility of dry matter, crude protein and ether extract.
\end{abstract}

Keywords: essential oils, additives, fructooligosaccharide

Recebido em 1 de outubro de 2014

Aceito em 7 de agosto de 2015

E-mail: liliane_borsatti@yahoo.com.br 


\section{INTRODUÇÃO}

Os sistemas de produção atuais de frangos de corte estão expostos a vários microrganismos patogênicos, e a utilização de promotores de crescimento à base de agentes antibacterianos na dieta é uma prática frequente e rotineira. Mesmo com o uso de altos padrões tecnológicos, não se consegue assegurar que o ambiente de criação das aves esteja livre de patógenos.

Quando presentes, esses patógenos prejudicam a eficiência de aproveitamento dos nutrientes das rações, em decorrência do possível surgimento de desordens entéricas. No entanto, o uso de antibióticos como antimicrobianos vem sofrendo restrições nos últimos anos, devido à possibilidade de seleção de microrganismos resistentes e à exigência de produtos livres de resíduos de antibióticos pelo mercado consumidor (Ramos et al., 2011).

Como alternativa para a produção animal, tem-se uma substituição dos antibióticos por produtos que os consumidores consideram "naturais". Com diferentes graus de sucesso, várias alternativas naturais têm sido desenvolvidas, como prebióticos, que são aditivos zootécnicos cuja principal forma de ação é a estimulação do crescimento e/ou ativação do metabolismo de algum grupo de bactérias benéficas do trato gastrintestinal (Silva e Nornberg, 2003), bem como óleos vegetais e extratos de plantas, os quais são substâncias derivadas de plantas medicinais que têm efeito positivo sobre a produção e a saúde dos animais (Perić et al., 2009). Esses produtos podem inibir o crescimento microbiano no intestino e melhorar a digestibilidade dos nutrientes, e são reconhecidos como seguros pela agência americana que regula remédios e alimentos (Food and Drug Administration, FDA) (Jang et al., 2007), além de estimularem a resposta imune do animal (Mellor, 2000).

De acordo com Godoi et al. (2008), os prebióticos mais estudados e utilizados na avicultura são os oligossacarídeos, dentre os quais se destacam os frutoligossacarídeos (FOS), produtos da indústria que, quando adicionados às rações, fornecem carboidratos fermentáveis para as bactérias benéficas que habitam o trato gastrintestinal, minimizando as populações de bactérias patogênicas, como a Escherichia coli e a Salmonella spp., por exclusão competitiva (Scapinello et al., 2001).

Em geral, as alternativas que podem substituir os antibióticos alteram a microbiota entérica, tornando-a mais estável e benéfica, capaz de proporcionar melhor desempenho para os animais, diminuir a contaminação das aves e das carcaças por bactérias patogênicas, sem deixar resíduos nocivos que possam causar problemas de saúde aos consumidores finais da carne de frango (Huyghebaert et al., 2011).

Dessa forma, o objetivo deste estudo foi avaliar a utilização de promotores de crescimento em rações para frangos de corte, dos 22 aos 32 dias de idade, bem como seus efeitos sobre as digestibilidades ileal e total de nutrientes e sobre o metabolismo energético.

\section{MATERIAL E MÉTODOS}

Todos os procedimentos deste estudo foram aprovados pelo Comitê de Ética e Pesquisa da Universidade Federal do Oeste do Paraná Unioeste, sob número de protocolo 63/10.

O experimento foi realizado na Fazenda Experimental Professor Dr. Antônio Carlos dos Santos Pessoa, pertencente à Universidade Estadual do Oeste do Paraná - Unioeste, localizada em Marechal Cândido Rondon Paraná - Brasil, com o intuito de avaliar o efeito do uso de diferentes promotores de crescimento sobre a digestibilidade dos nutrientes das rações.

Foram utilizados 180 pintos de corte da linhagem Cobb, divididos em 36 gaiolas metabólicas, com cinco aves por unidade experimental. De um a 21 dias de idade, as aves foram criadas em aviário experimental, onde receberam água e ração à vontade, sendo a ração formulada à base de milho e farelo de soja, conforme exigências nutricionais propostas por Rostagno et al. (2005), para as fases de um-10 e 11-21 dias de idade.

Para a fase de crescimento, de 22 a 32 dias de idade, foram formuladas duas dietas experimentais (Tab. 1), sendo uma dieta atendendo às exigências nutricionais para frangos de corte machos, de desempenho superior, e uma dieta com redução de $5 \%$ da exigência nutricional para cada uma das fases estudadas. A ração foi suplementada com óxido crômico, utilizado como marcador, e fornecida à vontade para as aves. 
Digestibilidade de nutrientes...

Tabela 1. Composição das rações experimentais utilizadas

\begin{tabular}{|c|c|c|}
\hline \multirow{2}{*}{ Ingredientes (kg) } & \multicolumn{2}{|c|}{22 a 35 dias de idade } \\
\hline & Normal & Reduzida \\
\hline Milho grão & 59,51 & 66,91 \\
\hline Farelo de soja & 31,85 & 28,4 \\
\hline Óleo de soja & 4,51 & 0,79 \\
\hline Fosf. bicálcico & 1,69 & 1,58 \\
\hline Calcário & 0,85 & 0,83 \\
\hline Sal comum & 0,40 & 0,40 \\
\hline Inerte $^{1}$ & 0,40 & 0,40 \\
\hline DL - Metionina & 0,25 & 0,22 \\
\hline L - Lisina HCL & 0,21 & 0,23 \\
\hline L - Treonina & 0,05 & 0,05 \\
\hline Suplemento vitamínico ${ }^{2}$ & 0,10 & 0,10 \\
\hline Cloreto de colina $60 \%$ & 0,06 & 0,06 \\
\hline Suplemento mineral ${ }^{3}$ & 0,05 & 0,05 \\
\hline Antioxidante $^{4}$ & 0,02 & 0,02 \\
\hline Total & 100,0 & 100,0 \\
\hline \multicolumn{3}{|l|}{ Nutrientes } \\
\hline Energia metabolizável (kcal/kg) & 3150 & 2992 \\
\hline Proteína bruta (\%) & 19,37 & 18,40 \\
\hline Cálcio (\%) & 0,84 & 0,79 \\
\hline Fósf. disponível (\%) & 0,42 & 0,40 \\
\hline Sódio $(\%)$ & 0,21 & 0,20 \\
\hline Potássio (\%) & 0,60 & 0,57 \\
\hline Lisina digestível (\%) & 1,10 & 1,04 \\
\hline Met + Cis digestível (\%) & 0,79 & 0,75 \\
\hline Metionina digestível (\%) & 0,44 & 0,42 \\
\hline Treonina digestível (\%) & 0,71 & 0,67 \\
\hline Valina digestível (\%) & 0,85 & 0,81 \\
\hline
\end{tabular}

${ }^{\text {TAreia }}$

${ }^{2}$ Suplemento vitamínico - Rovimix Aves: vit. A - 9000UI; vit. D3 - 2500UI; vit. E - 20UI; vit K3 - 2500mg; vit. B1 1500mg; vit. B2 - 6000mg; vit. B6 - 3000mg; vit. B12 - 12000mcg; biotina - 60mg; ác. fólico - 800mg; ác. nicotínico - 25000mg; ác. panteônico - 12000mg; selênio - 250mg.

${ }^{3}$ Suplemento mineral - Roligomix Aves: manganês - 160mg; ferro - 100mg; zinco - $100 \mathrm{mg}$; cobre - 20mg; cobalto 2mg; iodo - 2mg; ${ }^{4} \mathrm{BHT}$.

As aves foram distribuídas em um delineamento experimental inteiramente ao acaso, com seis tratamentos e oito repetições, em um esquema fatorial $2 \times 3$ (duas exigências nutricionais e três promotores de crescimento), conforme descrito:

tratamento 1 - dieta controle positivo - dieta atendendo às exigências nutricionais de cada fase, com adição de antibióticos (enramicina $10 \mathrm{~g} /$ ton e salinomicina $125 \mathrm{~g} /$ ton); tratamento 2 dieta com blend de óleos essenciais + frutoligossacarídeo (FOS) - dieta atendendo às exigências nutricionais de cada fase, com adição de um blend de óleos essenciais + FOS; tratamento 3 - dieta controle negativo - dieta atendendo às exigências nutricionais de cada fase, sem adição de promotores de crescimento; tratamento 4 - dieta controle positivo reduzida dieta formulada com redução de $5 \%$ da exigência nutricional, com adição de antibióticos (enramicina $10 \mathrm{~g} /$ ton e salinomicina $125 \mathrm{~g} /$ ton); tratamento 5 - dieta controle com blend óleos essenciais + FOS reduzida - dieta formulada com redução de 5\% das exigências nutricionais, com adição de óleos essenciais + FOS; tratamento 6 - dieta controle negativo reduzida dieta formulada com redução de $5 \%$ das exigências nutricionais, sem adição de promotores de crescimento. O blend de óleos essenciais utilizado era composto por orégano, anis, limão e inulina.

O período experimental teve duração de 10 dias, sendo cinco de adaptação e cinco de coleta total 
das excretas, realizadas a cada 12 horas para evitar fermentação, sendo estas homogeneizadas, pesadas e armazenadas $\left(-18^{\circ} \mathrm{C}\right)$. O consumo de ração foi calculado pela diferença da quantidade de ração fornecida e a sobra. Uma amostra representativa das rações e excretas foi seca por 72 horas em estufa a $60^{\circ} \mathrm{C}$, para determinação de matéria seca (MS), nitrogênio $(\mathrm{N})$, extrato etéreo (EE) e energia bruta (EB), de acordo com Silva e Queiroz (2002). Com base nos resultados, foi calculado o valor de energia metabolizável aparente (EMA) e EMA corrigida pelo balanço de nitrogênio (EMAn).

No final do período experimental, todas as aves foram abatidas para coleta de digesta ileal, o conteúdo ileal foi seco em estuda a $60^{\circ} \mathrm{C}$ para realização das análises de $\mathrm{MS}$, proteína bruta (PB) e EE. As mesmas análises foram realizadas para as rações experimentais, e, com os resultados, foram determinados os coeficientes digestibilidade ileal da MS (CDIMS), da PB (CDIPB) e do EE (CDIEE). Também foram determinados os coeficientes de digestibilidade total da MS (CDTMS), da PB (CDTPB) e do EE (CDTEE).

Os dados foram analisados por intermédio do SAS (2001), mediante análise de variância. Para comparação das médias, foi usado o teste de média Student Newman Keuls (SNK) ao nível de $5 \%$ de probabilidade.

\section{RESULTADOS E DISCUSSÕES}

Os valores dos CDIMS não diferiram $(\mathrm{P}>0,05)$ entre os aditivos para a dieta normal, porém, quando se reduziu a exigência nutricional, a dieta com antibiótico apresentou menor CDIMS (Tab. 2).

De acordo com Barbosa et al. (2008), o CDIMS reflete a digestibilidade dos nutrientes, ou seja, um aumento desse coeficiente indica maior absorção dos nutrientes de uma dieta.

Tabela 2. Coeficientes de digestibilidade ileal da digesta de frangos de corte aos 31 dias de idade, (\%)

\begin{tabular}{ccccccc}
\multirow{2}{*}{ Tratamento } & \multicolumn{2}{c}{ CDIMS $^{1}$} & \multicolumn{2}{c}{ CDIPB $^{2}$} & \multicolumn{2}{c}{ CDIEE $^{3}$} \\
\cline { 2 - 6 } & Normal & Reduzida & Normal & Reduzida & Normal & Reduzida \\
\hline DCP $^{4}$ & $93,39 \mathrm{Aa}$ & $90,70 \mathrm{Bb}$ & $78,15 \mathrm{Aa}$ & $75,09 \mathrm{Bb}$ & $62,70 \mathrm{Aa}$ & $54,01 \mathrm{Bc}$ \\
DCOEF $^{5}$ & $93,06 \mathrm{Aa}$ & $93,25 \mathrm{Aa}$ & $77,69 \mathrm{Ba}$ & $80,58 \mathrm{Aa}$ & $63,56 \mathrm{Aa}$ & $61,63 \mathrm{Aa}$ \\
DCN $^{6}$ & $92,64 \mathrm{Aa}$ & $92,71 \mathrm{Aa}$ & $77,74 \mathrm{Aa}$ & $79,37 \mathrm{Aa}$ & $65,11 \mathrm{Aa}$ & $57,65 \mathrm{Bb}$ \\
\hline $\left.\mathrm{CV}^{2} \%\right)$ & \multicolumn{2}{c}{0,813} & \multicolumn{2}{c}{2,88} & \multicolumn{2}{c}{4,038} \\
\hline
\end{tabular}

Médias seguidas de letras maiúscula distintas na linha diferem entre si pelo teste $\mathrm{F}$ ao nível de $5 \%$ de probabilidade; médias seguidas de letras minúsculas distintas na coluna diferem entre si pelo teste de SNK ao nível de $5 \%$ de probabilidade; ${ }^{1}$ CDIMS - coeficiente de digestibilidade ileal da matéria seca; ${ }^{2} \mathrm{CDIPB}$ - coeficiente de digestibilidade ileal da proteína bruta; ${ }^{3} \mathrm{CDIEE}$ - coeficiente de digestibilidade ileal do extrato etéreo. ${ }^{4} \mathrm{DCP}$ - dieta controle positivo; ${ }^{5} \mathrm{DCOEF}$ - dieta controle com adição de óleos essenciais e frutoligossacarídeo; ${ }^{6} \mathrm{DCN}$ - dieta controle negativo; CV coeficiente de variação.

Para os valores de CDIPB, os promotores utilizados não apresentaram diferença $(\mathrm{P}<0,05)$ para dieta normal, porém, quando se reduziu a exigência nutricional, o CDPB da dieta controle positivo reduziu significativamente $(\mathrm{P}<0,05)$.

Bactérias intestinais competem com o hospedeiro por nutrientes fornecedores de energia (Baurhoo et al., 2009), e o fato de os óleos essenciais reduzirem a carga bacteriana pela acidificação do lúmen intestinal é a provável razão de esse promotor ter melhorado o CDIPB.

Os valores dos CDIEE foram significativamente diferente para dieta normal e reduzida para os tratamentos DCP e DCN $(\mathrm{P}<0,05)$, para o tratamento com DCOEF não se observou diferença entre as dietas, no entanto mostrou melhora significativa $(\mathrm{P}<0,05)$ na digestibilidade de $E E$ na dieta com redução nutricional e inclusão do blend de óleos essenciais e frutoligossacarídeo. Resultados contrários a esses foram observados por Mountzouris et al. (2011), quando avaliaram o efeito de níveis de inclusão de óleos essenciais que compreendia uma mistura de erva-doce, orégano e cítricos sobre a digestibilidade de nutrientes. Os autores constataram que o CDIEE foi maior quando se utilizou antibiótico na ração.

A adição do blend de óleos essenciais + FOS na ração deste estudo melhorou a digestibilidade 
dos nutrientes mesmo quando se reduziu a exigência nutricional da dieta. De acordo com a literatura, a adição de extratos vegetais na dieta pode aumentar a secreção de suco gástrico, suco pancreático, sais biliares e enzimas do intestino delgado em ratos (Platel e Srinivasan, 1996; Wang e Bourne, 1998). A presença dessas substâncias na dieta proporciona aumento na produção de pepsina e ácido gástrico pelo organismo e contribui para a redução do $\mathrm{pH}$ estomacal e do intestino delgado, estimulando a secreção pancreática (Mellor, 2000). Essa pode ser uma das explicações para a dieta com óleos essenciais ter acarretado melhora na digestibilidade da matéria seca.
Os valores de CDTMS, CDTPB e CDTEE apresentaram efeito significativo $(\mathrm{P}<0,05)$ na dieta normal e na reduzida para as rações (Tab. 3), quando se observou que, reduzindo a exigência nutricional da dieta, reduz-se também a digestibilidade dos nutrientes. Para os resultados de EE, houve diferença significativa $(\mathrm{P}<0,05)$ entre os promotores utilizados. A dieta com redução da exigência nutricional contendo antibiótico apresentou menor coeficiente de digestibilidade, diferindo, assim $(\mathrm{P}<0,05)$, da dieta controle (sem antibiótico) e da dieta com óleos essenciais + FOS.

Tabela 3. Coeficientes de digestibilidade total da digesta ileal de frangos de corte aos 31 dias de idade, $(\%)$

\begin{tabular}{ccccccc}
\hline \multirow{2}{*}{ Tratamento } & \multicolumn{2}{c}{ CDTMS $^{1}$} & \multicolumn{2}{c}{ CDTPB $^{2}$} & \multicolumn{2}{c}{ CDTEE $^{3}$} \\
\cline { 2 - 6 } & Normal & Reduzida & Normal & Reduzida & Normal & Reduzida \\
\hline DCP $^{4}$ & $93,39 \mathrm{Aa}$ & $90,70 \mathrm{Bb}$ & $78,15 \mathrm{Aa}$ & $75,09 \mathrm{Bb}$ & $62,70 \mathrm{Aa}$ & $54,01 \mathrm{Bc}$ \\
DCOEF $^{5}$ & $93,06 \mathrm{Aa}$ & $93,25 \mathrm{Aa}$ & $77,69 \mathrm{Ba}$ & $80,58 \mathrm{Aa}$ & $63,56 \mathrm{Aa}$ & $61,63 \mathrm{Aa}$ \\
DCN $^{6}$ & $92,64 \mathrm{Aa}$ & $92,71 \mathrm{Aa}$ & $77,74 \mathrm{Aa}$ & $79,37 \mathrm{Aa}$ & $65,11 \mathrm{Aa}$ & $57,65 \mathrm{Bb}$ \\
\hline CV $(\%)$ & \multicolumn{2}{c}{0,813} & \multicolumn{2}{c}{2,88} & \multicolumn{2}{c}{4,038} \\
\hline
\end{tabular}

Médias seguidas de letras maiúscula distintas na linha diferem entre si pelo teste $\mathrm{F}$ ao nível de $5 \%$ de probabilidade; médias seguidas de letras minúsculas distintas na coluna diferem entre si pelo teste de SNK ao nível de $5 \%$ de probabilidade; ${ }^{1}$ CDTMS - coeficiente de digestibilidade total da matéria seca; ${ }^{2}$ CDTPB - coeficiente de digestibilidade total da proteína bruta; ${ }^{3} \mathrm{CDTEE}$ - coeficiente de digestibilidade total do extrato etéreo. ${ }^{4} \mathrm{DCP}$ - dieta controle positivo; ${ }^{5}$ DCOEF - dieta controle com adição de óleos essenciais e frutoligossacarídeo; ${ }^{6}$ DCN - dieta controle negativo; CV - coeficiente de variação.

Neste trabalho, os valores de CDTPB apresentaram-se menores quando comparados aos valores de CDIPB, devido ao fato de as análises do coeficiente de digestibilidade total não terem sido corrigidas pela excreção de ácido úrico presente nas excretas das aves.

A suplementação de dietas de frangos de corte na fase final de criação com uma mistura de sálvia, tomilho e alecrim ou com produto comercial à base de capsaicina, cinamaldeído e carvacrol proporcionou digestibilidade ileal da MS e da PB semelhante à ração contendo antibióticos e significativamente superior à ração controle (García et al., 2007).

A quantidade de nutrientes disponível na dieta reduzida pode ter influenciado na digestibilidade, influindo no desempenho final das aves, como foi observado em um experimento de desempenho conduzido paralelamente.
De acordo com Mellor (2000), dietas com extratos vegetais podem favorecer a secreção enzimática e melhorar a digestibilidade dos nutrientes por estimularem a produção de saliva e dos sucos gástrico e pancreático.

Hernández et al. (2004) observaram aumento no coeficiente de digestibilidade da MS em relação à ração controle, quando da suplementação da dieta com extratos vegetais à base de orégano, canela, pimenta, sálvia, tomilho e alecrim, sendo encontradas diferenças significativas para as fases inicial e de terminação de frangos de corte.

Na Tabela 4, encontram-se os valores de EMA e EMAn das dietas experimentais.

Em estudo realizado por Rostagno et al. (2001), a EMAn e a digestibilidade ileal da proteína bruta da dieta de frangos de corte foram semelhantes entre dietas com extratos vegetais e com antibióticos. 
Por outro lado, estudos realizados com frangos de corte mantidos com dietas contendo extratos vegetais isolados (Barreto, 2008) comprovaram que não houve diferenças na EMAn das dietas.

Amad et al. (2011), ao avaliarem o efeito de óleo essencial de tomilho e anis sobre crescimento, desempenho e digestibilidade ileal de nutrientes em frangos de corte, observaram que a digestibilidade da proteína bruta, do extrato etéreo, do cálcio e do fósforo foi significativamente maior nas aves alimentadas com ração contendo esse aditivo do que a digestibilidade das aves do grupo controle.

Tabela 4. Energia metabolizável aparente (EMA) e EMA corrigida pelo balanço de nitrogênio (EMAn) de frangos de corte aos 31 dias de idade

\begin{tabular}{ccccc}
\hline \multirow{2}{*}{ Tratamento } & \multicolumn{2}{c}{ EMA (kcal/kg) } & \multicolumn{2}{c}{ EMAn $(\mathrm{kcal} / \mathrm{kg})$} \\
\cline { 2 - 5 } & Normal & Reduzida & Normal & Reduzida \\
\hline DCP $^{1}$ & 3117 & 2875 & 2939 & 2714 \\
DCOEF $^{2}$ & 3181 & 2910 & 3000 & 2749 \\
DCN $^{3}$ & 3115 & 2940 & 2945 & 2784 \\
MÉDIA & $3138^{\mathrm{A}}$ & $2908^{\mathrm{B}}$ & $2961^{\mathrm{A}}$ & $2749^{\mathrm{B}}$ \\
\hline CV (\%) & \multicolumn{3}{c}{4,536} \\
\hline
\end{tabular}

Médias seguidas de letras maiúscula distintas na linha diferem entre si pelo teste $\mathrm{F}$ ao nível de $5 \%$ de probabilidade; médias seguidas de letras minúsculas distintas na coluna diferem entre si pelo teste de SNK ao nível de 5\% de probabilidade; ${ }^{1}$ DCP - dieta controle positivo; ${ }^{2} \mathrm{DCOEF}$ - dieta controle com adição de óleos essenciais e frutoligossacarídeo; ${ }^{3} \mathrm{DCN}$ - dieta controle negativo; CV - coeficiente de variação.

\section{CONCLUSÃO}

De acordo com os resultados do presente estudo, a ração suplementada com óleos essenciais e frutoligossacarídeos apresentou resultados satisfatórios, não diferindo da dieta com antibiótico quando atendidas as exigências nutricionais das aves. Contudo, quando os níveis nutricionais foram reduzidos, a ração com óleos essenciais e frutoligossacarídeos mostrou melhores resultados, corroborando a eficácia desses prebióticos em substituição aos antibióticos na dieta para frangos de corte.

\section{REFERÊNCIAS}

AMAD, A.A.; MÄNNER, K.; WENDLER, K.R. et al. Effects of a phytogenic feed additive on growth performance and ileal nutrient digestibility in broiler chickens. Poult. Sci., v.90, p.2811-2816, 2011.

BARBOSA, N.A.A.; SAKOMURA, N.K.; FERNANDES, J.B.K.; DOURADO, L.R.B. Enzimas exógenas no desempenho e na digestibilidade ileal de nutrientes em frangos de corte. Pesqui. Agropecu. Bras., v.43, p.755-762, 2008.

BARRETO, M.S.R.; MENTEN, J.F.M.; RACANICCI, A.M.C. et al. Plant extracts used as growth promoters in broilers. Braz. J. Poult. Sci., v.10, p.109-115, 2008.
BAURHOO, B.; FERKET, P.R.; ZHAO, X. Effects of diets containing different concentrations of mannanoligosaccharide or antibiotics on growth performance, intestinal development, cecal and litter microbial populations, and carcass parameters of broilers. Poult. Sci., v.88, p.2262-2272, 2009.

GARCÍA， V.; CATALÁ-GREGORI， P.; HERNANDÉZ, F. et al. Effect of formic acid plant extracts on growth, nutrient digestibility, intestine mucosa morphology, and meat yield of broilers. J. Appl. Poult. Res., v.16, p.555-562, 2007.

GODOI, M.J.S.; ALBINO, L.F.T.; ROSTAGNO, H.S. et al. Utilização de aditivos em rações formuladas com milho normal e de baixa qualidade para frangos de corte. Rev. Bras. Zootec., v.37, p.1005-1011, 2008.

HERNÁNDEZ, F.; MADRID, J.; GARCÍA, V.; ORENGO, J. et al. Influence of two plant extracts on broilers performance, digestibility, and digestive organ size. Poult. Sci. v.83, p.169174, 2004.

HUYGHEBAERT， G.; DUCATELLE， R.; IMMERSEEL, F.V. An update on alternatives to antimicrobial growth promoters for broilers. Vet. J., v.187, p.182-188, 2011. 
JANG, I.S.; KO, Y.H.; KANG, S.Y.; LEE, C.Y. Effect of a commercial essential oil on growth performance, digestive enzyme activity and intestinal microflora population in broiler chickens. Anim. Feed Sci. Tech, v.134, p.304315, 2007.

MELLOR, S. Herbs and spices promote health and growth. Pig Prog., v.16, p.18-21. 2000.

MOUNTZOURIS, K.C.; PARASKEVAS, V.; TSIRTSIKOS, P. et al. Assessment of a phytogenic feed additive effect on broiler growth performance, nutrient digestibility and caecal microflora composition. Anim. Feed Sci. Tech., p.223-231, 2011.

PLATEL, K.; SRINIVASAN, K. Influence of dietary spices or their active principles on digestive enzymes of small intestinal mucosa in rats. Int. J. Food Sci. Nutr., v.47, p.55-59, 1996.

PERIĆ, L.; ŽIKIĆ, D.; LUKIĆ, M. Application of alternative of growth promoters in broiler production. Biotech. Anim. Husb., v.25, p.387397, 2009.

RAMOS, L.S.N.; LOPES, J.B.; SILVA, S.M.M.S. et al. Desempenho e histomorfometria intestinal de frangos de corte de 1 a 21 dias de idade recebendo melhoradores de crescimento. Rev. Bras. Zootec., v.40, p.1738-1744, 2011.
ROSTAGNO, H.S. ALBINO, L.F.T.; TOLEDO, R.S.et al. Nutritional evaluation of the extract as an alternative to antibiotic growth promoters in broiler chickens diets. Degussa. Viçosa. p.11, 2001.

ROSTAGNO, H.S.; ALBIN, L.F.T.; DONZELE, J.L. Tabelas brasileiras para aves e suínos: composição de alimentos e exigências nutricionais. Viçosa, MG: UFV, Departamento de Zootecnia, 2005. 186p.

SAS Institute. 2001. SAS User's Guide: Statistics. Version 8.0 Edition. SAS Inst. Inc., Cary, NC.

SILVA, D. J; QUEIROZ, A.C. Análises de alimentos: métodos químicos e biológicos. 3.ed. Viçosa, MG: UFV, 2002. 235p.

SILVA, L.P.; NORBERG, J.L. Prebióticos na nutrição de não ruminantes. Ciênc. Rural, v.33, p.983-990, 2003.

SCAPINELLO, C.; FARIA, H. G.; FURLAN, A. L. et al. Efeito da utilização de oligossacarídeo manose e acidificantes sobre o desempenho de coelhos em crescimento. Rev. Bras. Zootec., v.30, p.1272- 1277, 2001.

WANG, R.; LI, D.; BOURNE, S. Can 2000 years of herbal medicine history help us solve problems in year 2000. In: ALLTECH'S ANNUAL SYMPOSIUM, 14., Nottingham. Proceedings... Nottingham: ALLTECH, 1998. p.168-184. 